\title{
Dilatation and curettage versus manual vacuum aspiration for first trimester clandestine abortions
}

\section{Elie Nkwabong*, Joseph Nelson Fomulu}

\begin{abstract}
Department ofof Obstetrics \& Gynecology, Faculty of Medicine and Biomedical Sciences/University Teaching
\end{abstract} Hospital, Yaoundé, Cameroon

Received: 20 March 2015

Revised: 31 March 2015

Accepted: 09 May 2015

\author{
*Correspondence: \\ Dr. Elie Nkwabong, \\ E-mail: enkwabong@yahoo.fr
}

Copyright: () the author(s), publisher and licensee Medip Academy. This is an open-access article distributed under the terms of the Creative Commons Attribution Non-Commercial License, which permits unrestricted non-commercial use, distribution, and reproduction in any medium, provided the original work is properly cited.

\begin{abstract}
Background: Unintended pregnancy rate is rising worldwide and most of these pregnancies end by clandestine abortion. This study aimed at comparing complications of clandestine abortions done with Manual Vacuum Aspiration (MVA) to those of clandestine abortions done with Dilatation and Curettage (D\&C).

Methods: This retrospective descriptive study was carried out in the Yaoundé University Teaching Hospital (Cameroon) from March 1st to August 31st, 2012. Abortions carried out with MVA or D\&C were recruited. Main variables studied were abortionist, method used, complications presented and hospital stay. Data were analyzed using SPSS 18.0. Analyses included the $t$ test and the Fisher exact test. The level of significance was $P<0.05$.

Results: Main abortionists were nurses and general practitioners. Compared to MVA, women in the D\&C group had more uterine perforations $(\mathrm{P}=0.004)$, severe anemia (OR 1.5, 95\% CI 0.5-4.3), prolonged hospital stay $(\mathrm{P}=0.018)$ and maternal death (one case). D\&C done by nurses carried more risk of severe complications (OR 3.6, 95\% CI 0.2-53.8). Conclusions: MVA constitutes a safer method than D\&C. However, abortionists should receive adequate training before using MVA.
\end{abstract}

Keywords: Clandestine abortions, Manual vacuum aspiration, Dilatation and curettage, Complications

\section{INTRODUCTION}

Unintended pregnancy rate is rising worldwide. ${ }^{1}$ Some of the reasons in developing countries include the lack of sufficient knowledge on sexual education and reproduction, irregular supply of contraceptive methods, contraceptive failure or fear to use contraceptive methods. ${ }^{2,3}$ Only $14 \%$ of Cameroonian women of reproductive age were using modern contraceptive methods in 2011. ${ }^{4}$ Most women with unintended pregnancy try to terminate them. Abortion is still illegal in Cameroon and discussions on its legalization have always ended prematurely. For this reason, women seeking abortion can only carry them out clandestinely.
Abortion is legal in Cameroon only in cases of rape or incest. $^{5,6}$

The rate of unsafe abortions worldwide is still increasing, ${ }^{1}$ this rate was $49 \%$ in 2008 compared to $44 \%$ in 1995. ${ }^{7}$ Unsafe abortion is being practiced since antiquity. It continues to be practiced today as a method of birth control. Various methods of inducing abortion exist and include medical, surgical and even traditional methods. ${ }^{8,9}$

Manual Vacuum Aspiration (MVA) for pregnancy termination has been used since many decades. Compared to Dilatation and Curettage (D\&C), MVA is safer in terminating first trimester pregnancies. ${ }^{10,11}$ 
Furthermore, MVA is more cost-effective $e^{10,12}$ and less time consuming when compared to D\&C. ${ }^{10}$ In Cameroon, therefore, MVA is being preferred for pregnancy termination by many abortionists despite their lack of sufficient training in the use of this method while others are still using D\&C. Hence, some complications are awaited. No study in our country has evaluated clandestine abortions using $\mathrm{D} \& \mathrm{C}$ versus MVA in terminating pregnancy. The aim of this study therefore was to evaluate the complications of clandestine abortion using the two methods.

\section{METHODS}

This retrospective study was conducted between March $1^{\text {st }}$ and August $31^{\text {st }}, 2012$ (six months) in the maternity of the University Teaching Hospital, Yaoundé, Cameroon. Medical records of all women whose first trimester clandestine abortion ( $\leq 14$ weeks) were done with $\mathrm{D} \& \mathrm{C}$ or MVA were recruited.

Women who performed clandestine abortions were received and examined by the resident assisted sometimes by the gynecologist, after which a diagnosis was made. The investigations, if necessary, were prescribed under the gynecologist's supervision. After explaining the diagnosis and the different treatment modalities to the patient, an informed consent was obtained from her. Then, the proposed treatment was done by the gynecologist or under his supervision and follow-up was performed under the gynecologist's supervision. All data collected from admission to discharge were written in patients' files.

In our study data were extracted from patients' files by the principal investigator. Data collected on a pretested questionnaire included maternal age, parity, marital status, occupation, Gestational Age (GA) at abortion, the number of previous induced abortions, the abortionist, the method of abortion used (obtained from patient's description of the procedure), the duration of antibiotic coverage, complications presented and the duration of hospital stay in our unit. GA was obtained from an ultrasound scan performed to diagnose the pregnancy if any, or from last menstrual period but validated by bimanual vaginal examination.

This study received approval from the institutional ethics committee. The necessary sample size was calculated as needing at least 62 women who presented with complications following clandestine abortions. Data were analyzed using SPSS 18.0. Data of women whose abortions were carried out with $\mathrm{D} \& \mathrm{C}$ were compared with those of women whose abortions were done using MVA. A complication was said to be severe if it was either lethal, or if there were post abortal sepsis (incomplete septic abortion, pelvic infection, septic shock), severe anemia $(\mathrm{Hb}<7 \mathrm{~g} / \mathrm{dl})$, hypovolemic shock (systolic blood pressure $<80 \mathrm{mmHg}$ ), uterine perforation with or without peritonitis. A complication was considered mild if there was only an incomplete abortion. The t-test and the Fisher exact test were used for comparison. The significance level was $\mathrm{P}<0.05$.

Footnote: To calculate the sample size, the following formula for descriptive studies $\mathrm{N}=\mathrm{P}(1-\mathrm{P}) \mathrm{Z}^{2} / \mathrm{D}^{2}$ was used where $\mathrm{Z} \alpha=$ 1.96 corresponds to a confidence level of $0.05, \mathrm{D}=0.1$ is the degree of precision and assuming that the prevalence of complications following clandestine abortion (P) might be $20 \%$ in Yaoundé.

\section{RESULTS}

During the study period, a total of 65 clandestine abortions were carried out. Of these, 37 (56.9\%) were performed using MVA and $28(43.1 \%)$ by D\&C. Data are given in Table 1.

Table 1: Distribution of some data in both groups.

\begin{tabular}{|c|c|c|c|c|c|}
\hline Variables & MVA (range) & D\&C (range) & OR & $95 \% \mathrm{CI}$ & P value \\
\hline Maternal ages (years) & $24.1 \pm 4.4(17-36)$ & $25.1 \pm 5.4(18-41)$ & & & 0.41 \\
\hline Parities & $1.3 \pm 1.4(0-5)$ & $1.6 \pm 1.7(0-5)$ & & & 0.43 \\
\hline Previous clandestine abortion & $19 / 37(51.4 \%)$ & $7 / 28(25 \%)$ & 0.3 & $0.1-0.9$ & \\
\hline Gestational ages (weeks) & $10.5 \pm 2.2(5-13)$ & $11.2 \pm 3.7(6-14)$ & & & 0.34 \\
\hline Antibiotic coverage (days) & $3.1 \pm 2.8(1-10)$ & $4.3 \pm 3.9(1-14)$ & & & 0.15 \\
\hline Hospital stay (days) & $2.8 \pm 2.9(0-17)$ & $5.0 \pm 4.4(1-21)$ & & & 0.018 \\
\hline
\end{tabular}

MVA: Manual vacuum aspiration, D\&C: Dilatation \& curettage, OR: Odds Ratio

Most women in both groups were students or housewives. Indeed, 21 women $(56.8 \%)$ were students in the MVA group as against $13(46.4 \%)$ in the D\&C group and 11 women $(29.7 \%)$ were housewives in the MVA group as against five $(17.9 \%)$ in the D\&C group.
Concerning marital status, four women (14.3\%) were married in the D\&C group and seven (18.9\%) in the MVA group. Twenty two women $(78.6 \%)$ were single in the D\&C group as against thirty $(81.1 \%)$ in the MVA 
group. We had one case of a widow and one divorcee in the $\mathrm{D} \& \mathrm{C}$ group.

The gestational ages ranged between 5 and 13 weeks in the MVA group and between 6 and 14 in the D\&C group (Table 2).

Table 2: Distribution of gestational age at abortion according to method used.

\begin{tabular}{|lll|}
$\begin{array}{l}\text { Gestational age } \\
\text { (weeks) }\end{array}$ & MVA & D\&C \\
\hline $5-7$ & $4(10.8)$ & $3(10.7)$ \\
\hline $8-9$ & $8(21.6)$ & $8(28.6)$ \\
\hline $10-11$ & $13(35.1)$ & $10(35.7)$ \\
\hline $12-14$ & $12(32.5)$ & $7(25)$ \\
\hline Total & $37(100)$ & $28(100)$ \\
\hline
\end{tabular}

MVA: Manual vacuum aspiration, D\&C: Dilatation \& curettage
Main abortionists were nurses involved in 24 cases $(85.7 \%)$ in the D\&C group and 26 cases $(70.3 \%)$ in the MVA group. General practitioners were involved in four cases $(14.3 \%)$ in the D\&C group and in 11 cases $(29.7 \%)$ in the MVA group. D\&C done by nurses were associated with an increased risk of severe complications than those done by physicians (OR 3.6, 95\%CI 0.2-53.8), though not statistically significant $(\mathrm{P}=0.38)$. There was no increased risk between two groups when procedure was performed using MVA (OR 1.01, 95\%CI 0.2-4.9) (Table 3).

The procedures were conducted in primary health centers or in the provider's home in 44 cases $(67.7 \%)$ and in a private clinic or a hospital in 21 cases $(32.3 \%)$.

After the procedure, antibiotic coverage was used in 31 cases $(83.8 \%)$ in the MVA group and in 25 cases $(89.3 \%)$ in the $\mathrm{D} \& \mathrm{C}$ group.

Table 3: Complications among the 65 women according to abortion providers and methods.

\begin{tabular}{|c|c|c|c|c|c|c|}
\hline \multicolumn{2}{|c|}{$\begin{array}{l}\text { Methods and abortion } \\
\text { providers }\end{array}$} & $\begin{array}{l}\text { SC } \\
\mathbf{N}(\%)\end{array}$ & $\begin{array}{l}\text { MC } \\
\mathbf{N}(\%)\end{array}$ & OR & $95 \% \mathrm{CI}$ & $\mathbf{P}$ \\
\hline \multirow{2}{*}{ MVA } & Nurses & $19(29.2)$ & $7(10.8)$ & \multirow{2}{*}{1.01} & \multirow{2}{*}{$0.2-4.9$} & \multirow{2}{*}{1} \\
\hline & Physicians & $8(12.3)$ & $3(4.6)$ & & & \\
\hline \multirow{2}{*}{$\mathrm{D} \& \mathrm{C}$} & Nurses & $22(33.9)$ & $2(3.0)$ & \multirow{2}{*}{3.6} & \multirow{2}{*}{$0.2-53.8$} & \multirow{2}{*}{0.38} \\
\hline & Physicians & $3(4.6)$ & $1(1.5)$ & & & \\
\hline Total & & $52(80)$ & $13(20)$ & & & \\
\hline
\end{tabular}

SC: Severe complications, MC: Mild complications, OR: Odds Ratio

The main complications observed in the $\mathrm{D} \& \mathrm{C}$ group were uterine perforation (six cases as against zero) $(\mathrm{P}=0.004)$, severe anemia (OR 1.5, 95\%CI 0.5-4.3), post abortal peritonitis (two cases) and maternal death (one case) while in the MVA group incomplete abortion, hypovolemic shock and post abortal pelvic infection were most recorded (Table 4).

Table 4: Distribution of complications according to methods used.

\begin{tabular}{|llllll|}
\hline Complications & MVA & D\&C & OR & $95 \%$ CI & P value \\
\hline Severe anemia & $10(27.0)$ & $10(35.7)$ & 1.5 & $0.5-4.3$ & 0.58 \\
\hline Pelvic infection & $8(21.6)$ & $4(14.3)$ & 0.6 & $0.1-2.2$ & 0.53 \\
\hline Hypovolemic shock & $8(21.6)$ & $2(7.1)$ & 0.2 & $0.06-1.4$ & 0.16 \\
\hline Incomplete abortions & $10(27.0)$ & $3(10.7)$ & 0.3 & $0.07-1.3$ & 0.12 \\
\hline Uterine perforation & $0(0)$ & $6(21.4)$ & - & - & 0.004 \\
\hline Generalized peritonitis & $0(0)$ & $2(7.1)$ & - & - & 0.18 \\
\hline Septic shock & $1(2.7)$ & $0(0)$ & - & - & 1 \\
\hline Maternal death & $0(0)$ & $1(3.6)$ & - & - & 0.43 \\
\hline Total & $37(100)$ & $28(100)$ & & & \\
\hline
\end{tabular}

MVA: Manual vacuum aspiration, D\&C: Dilatation \& curettage, OR: Odds Ratio 
The longest hospital stay (21 days) was in the D\&C group. Indeed, after abortion at 14 weeks this patient presented with a left tubo-ovarian abscess which ruptured and resulted in a generalized peritonitis. After laparotomy and drainage, the patient developed a burst abdomen, septic shock and finally died. The longest hospital stay in the MVA group (17 days) concerned a case of an abortion at 10 weeks gestation with subsequent post abortal infection which resulted in septic shock with acute renal failure which were treated successfully.

\section{DISCUSSION}

In our study, we observed that MVA was more often preferred to $\mathrm{D} \& \mathrm{C}$ in clandestine termination of pregnancy. No statistically significant difference was observed between the two groups concerning maternal age and parity. Women with past history of abortion were less found in the D\&C group than in the MVA group (OR 0.3 ). This can be explained by the fact that women who experienced previous clandestine abortions with MVA preferred for subsequent abortions abortionists who use MVA.

In both groups the majority of women were either students or housewives especially in MVA group. Regarding marital status, most women were single $(52 / 65$ or $80 \%$ ). Hence, induced abortions in our study were usually carried out by single women.

There was no statistically significant difference in the mean gestational age between the two groups. Although the main abortionists were nurses and general practitioners, the former used both methods (MVA and D\&C) while the latter preferred MVA more. In our country, physicians receive formal training in uterine evacuation procedures using either MVA or D\&C while nurses are trained on the field by doctors. MVA is simple to use if adequate training has been obtained. Jejeebhoy et al reported that trained nurses could perform the procedure as efficiently as physicians with the same complications rate. $^{13}$

Antibiotic cover after abortion was similar in both groups with no statistically significant difference in the mean duration of use in the two groups. In our series, six women in the D\&C group had uterine perforations as against none in the MVA group $(\mathrm{P}=0.004)$. Moreover, $\mathrm{D} \& \mathrm{C}$ was more associated with increased risk of severe anemia (though not statistically significant), generalized peritonitis and maternal death. Higher complications observed with D\&C have been reported elsewhere. ${ }^{10}$

The case of maternal death that occurred in the D\&C group was due to septic shock that developed after generalized peritonitis that followed dilatation and curettage at 14 weeks with late consultation (more than 2 months after abortion). Other complications observed with MVA in our series were incomplete abortions that might have led to pelvic infection or to hemorrhage with hypovolemic shock. In some series, amongst trained personnel the commonest complication associated with MVA was incomplete abortion. ${ }^{14}$ Lack of training in our series can explain the so many complications observed with MVA. According to some authors, MVA is safer and has almost the same outcome as medical termination of pregnancy with misoprostol. ${ }^{15}$

The mean hospital stay in our study was longer in the D\&C group with a statistically significant difference. This has also been reported by other authors. ${ }^{10}$ The commonest complication in D\&C group in our study was severe anemia in agreement with other series. ${ }^{10,11}$ The longest hospital stay was observed in the patient who died of septic shock. In fact after the abortion she developed a left tubo-ovarian abscess that ruptured into generalized peritonitis which was drained, but the patient developed a burst abdomen which was repaired, but she went into septic shock and died some hours later.

In this study D\&C was associated, more than MVA, with increased risk of severe anemia, uterine perforation and generalized peritonitis resulting in maternal death or a longer hospital stay. Therefore, D\&C should be abandoned, or should be practiced by trained physicians. To reduce risk of complications associated with MVA, we should emphasize again that health providers, especially nurses, should receive adequate training before using the method.

Funding: No funding sources

Conflict of interest: None declared

Ethical approval: The study was approved by the institutional ethics committee

\section{REFERENCES}

1. Shah I, Ahman E. Unsafe abortion in 2008: global and regional levels and trends. Reprod Health Matters. 2010;18:90-101.

2. Aniteye P, Mayhew S. Attitudes and experiences of women admitted to hospital with abortion complications in Ghana. Afr J Reprod Health. 2011;15:47-55.

3. Najafian M, Karami KB, Cheraghi M, Mohammad Jafari R. Prevalence of and some factors relating with unwanted pregnancy, in Ahwaz city, Iran, 2010. ISRN Obstet Gynecol. 2011;2011:523430.

4. Tran BX, Nguyen LT, Nguyen NH, Hoang QV, Hwang J, Okwusidi JI, et al. Cameroon demographic and health and multiple indicator survey (EDSMICS) 2011. Glob Health Action. 2013;6(2):19570.

5. United Nations. Abortion policies. In: UN, eds. A Global Review. Vol 1. Cameroon: United Nations; 2002: 81-82.

6. Schuster S. Women's experiences of the abortion law in Cameroon: "What really matters". Reprod Health Matters. 2010;18(35):137-44.

7. Sedgh G, Singh S, Shah IH, Ahman E, Henshaw SK, Bankole A. Induced abortion: incidence and trends 
worldwide from 1995 to 2008. Lancet. 2012 Feb;379(9816):625-32.

8. Grossman D, Holt K, Peña M, Lara D, Veatch M, Córdova D, et al. Self-induction of abortion among women in the United States. Reprod Health Matters. 2010 Nov;18(36):136-46.

9. Rasch V. Unsafe abortion and postabortion care - an overview. Acta Obstet Gynecol Scand. 2011 Jul;90(7):692-700.

10. Pereira PP, Oliveira AL, Cabar FR, Armelin AR, Maganha CA, Zugaib M. Comparative study of manual vacuum aspiration and uterine curettage for treatment of abortion. [Article in Portuguese]. Rev Assoc Med Bras. 2006;52:304-7.

11. Choobun T, Khanuengkitkong S, Pinjaroen S. A comparative study of cost of care and duration of management for first-trimester abortion with manual vacuum aspiration (MVA) and sharp curettage. Arch Gynecol Obstet. 2012;286:1161-4.

12. Hu D, Grossman D, Levin C, Blanchard K, Adanu R, Goldie SJ. Cost-effectiveness analysis of unsafe abortion and alternative first-trimester pregnancy termination strategies in Nigeria and Ghana. Afr $\mathbf{J}$ Reprod Health. 2010;14:85-103.

13. Jejeebhoy SJ, Kalyanwala S, Zavier AJ, Kumar R, Mundle S, Tank J, et al. Can nurses perform manual vacuum aspiration (MVA) as safely and effectively as physicians? Evidence from India. Contraception. 2011;84:615-21.

14. Meirik O, My Huong NT, Piaggio G, Bergel E, von Hertzen H. Complications of first-trimester abortion by vacuum aspiration after cervical preparation with and without misoprostol: a multicentre randomised trial. Lancet. 2012;379:1817-24.

15. Dabash R, Ramadan MC, Darwish E, Hassanein N, Blum J, Winikoff B. A randomized controlled trial of $400-\mu \mathrm{g}$ sublingual misoprostol versus manual vacuum aspiration for the treatment of incomplete abortion in two Egyptian hospitals. Int J Gynaecol Obstet. 2010;111:131-5.

DOI: $10.18203 / 2320-1770 . i j r \operatorname{cog} 20150079$

Cite this article as: Nkwabong E, Fomulu JN.

Dilatation and curettage versus manual vacuum aspiration for first trimester clandestine abortions. Int J Reprod Contracept Obstet Gynecol 2015;4:716-20. 